\title{
Chiral Symmetry Breaking of Thiohydantoins by Attrition-Enhanced Deracemization
}

Naohiro Uemura, Momoka Hosaka, Aoi Washio, Yasushi Yoshida, Takashi Mino, and Masami Sakamoto*

Department of Applied Chemistry and Biotechnology, Graduate School of Engineering, Chiba University, Yayoi-cho, Inage-ku, Chiba 263-8522, Japan 


\section{Table of Contents}

General information

Synthesis of thioureas 2

Synthesis of aroylformyl chlorides $\mathbf{3}$

Synthesis of thiohydantoin 1a-c

Spectral data of 1a

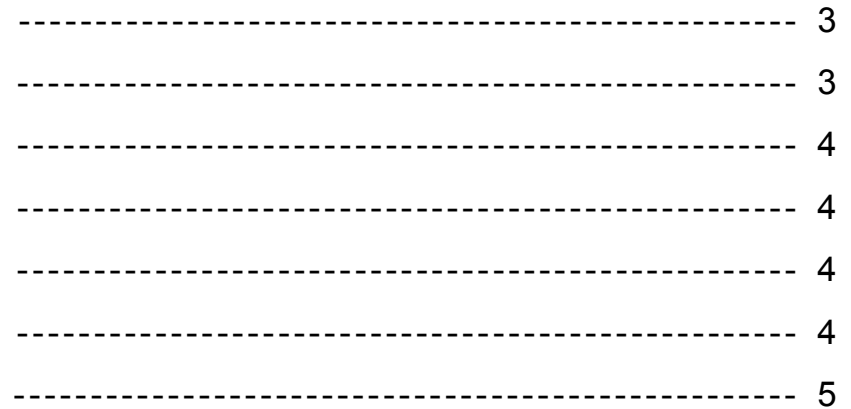

General procedure of dynamic crystallization

Enantioselectivity of deracemization

DFT calculation

Racemization of dimethylthiohydantoin $\mathbf{5}$

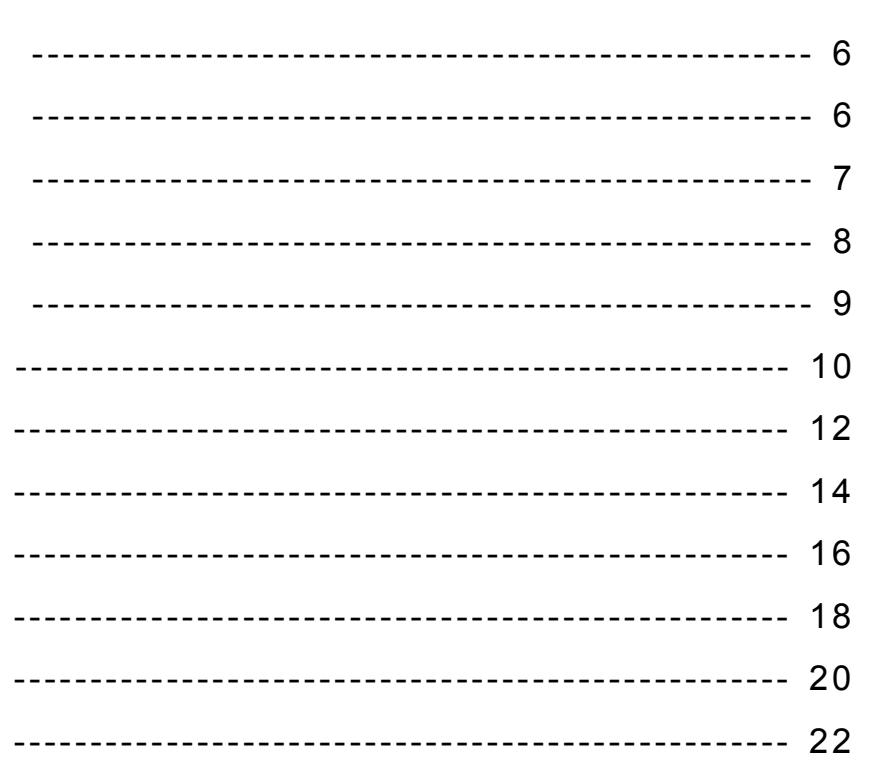

References

Single crystal X-Ray structure analysis of $\mathbf{1 a}$

Single crystal X-Ray structure analysis of $\mathbf{1 b}$

Single crystal X-Ray structure analysis of 1c

HPLC analysis of $\mathbf{1 a}$

HPLC analysis of $\mathbf{1 b}$

HPLC analysis of 1c

NMR spectrum of 1a

NMR spectrum of $\mathbf{1 b}$

NMR spectrum of $\mathbf{1 c}$

NMR spectrum of 5 
General Information

NMR spectra were recorded in $\mathrm{CDCl}_{3}$ solutions on a Bruker 300 spectrometer operating at 300 and $75 \mathrm{MHz}$, respectively, for ${ }^{1} \mathrm{H}$ and ${ }^{13} \mathrm{C}$ NMR. Chemical shifts are reported in parts per million (ppm) relative to TMS as an internal standard. IR spectra were recorded on a JASCO FT/IR-230 spectrometer. High- resolution mass spectrometry (HRMS) was performed on an Orbitrap ThermoFisher Exactive ion trap mass spectrometer. X-ray single crystallographic analysis was conducted using a APEX II ULTRA (Bruker AXS). In SHG experiment, A conventional Q-switched Nd/YAG laser (Quanta-Ray, GCR190) with a wavelength of $1064 \mathrm{~nm}$ and a pulse duration of 30 ns was used as light source, and CCD video camera (ELMO, CN43H) was used for monitor.

\section{Synthesis of thioureas 2}

To a toluene $(20 \mathrm{~mL})$ solution of isothiocyanates $(7.5 \mathrm{mmol})$, corresponding amine $(10 \mathrm{mmol})$ and a were added, and the solution was stirred for 1 hour at room temperature. After the solution was diluted with ethyl acetate (30 $\mathrm{mL})$ and washed with $1 \mathrm{M}$ aq. $\mathrm{HCl}(2 \times 30 \mathrm{~mL})$, aq. $\mathrm{NaHCO}_{3}(2 \times 30 \mathrm{~mL})$, saturated aq. $\mathrm{NaCl}(2 \times 30 \mathrm{~mL})$. The organic layers were dried over $\mathrm{MgSO}_{4}$ and filtered. The solvent was removed in vacuo. The obtained solid was purified by recrystallization from $\mathrm{CHCl}_{3} /$ hexane. The structure was determined the comparison with the reported spectral data for 1,3-dibenzylthiourea $\mathbf{2 a},{ }^{[\mathrm{S} 1]}$ and 1-isopropyl-3-phenylthiourea $\mathbf{2 b}, \mathbf{2}$. ${ }^{[S 2]}$

\section{Synthesis of aroylformyl chlorides 3}

All aroylformyl chrolides was prepared from corresponding aroylformic acid ${ }^{[\mathrm{S3} S 5]}$ and thionyl chloride. Thionyl chloride $(60 \mathrm{mmol})$ and dimethylformamide (ca. $0.5 \mathrm{~mL})$ were added to toluene $(20 \mathrm{~mL})$ solution of corresponding aroylformic acid $(30 \mathrm{mmol})$, and stirred for 2 hours at $65^{\circ} \mathrm{C}$. After then, toluene and excess thionyl chloride were removed in vacuo. Resulting acid chloride was used without further purification.

\section{Synthesis of thiohydantoin 1a-c}

Aroylformyl chloride $3(12 \mathrm{mmol})$ was added to THF $(10 \mathrm{~mL})$ solution of thiourea $2(10 \mathrm{mmol})$ and $\mathrm{Et}_{3} \mathrm{~N}(15$ $\mathrm{mmol}$ ) with stirring at room temperature. After confirming the consumption of thiourea 1 by using TLC (ca. 2-3 hours), the solution was diluted with ethyl acetate $(30 \mathrm{~mL})$ and washed with $1 \mathrm{M}$ aq. $\mathrm{HCl}(2 \times 30 \mathrm{~mL})$, saturated aq. $\mathrm{NaHCO}_{3}(2 \times 30 \mathrm{~mL})$, saturated aq. $\mathrm{NaCl}(2 \times 30 \mathrm{~mL})$. The organic layer was dried over $\mathrm{MgSO}_{4}$ and filtered. The solvent was removed in vacuo. The crude thiohydantoins were purified by silica gel column chromatography and recrystallized from $\mathrm{CHCl}_{3}$ / hexane.

\section{(R)-(+)-1,3-Dibenzyl-5-hydroxy-5-(3-nitrophenyl)-2-thiohydantoin 1a}

Optical rotation: +121 (90 \% ee) (c=1.0 in $\left.\mathrm{CHCl}_{3}\right)$; colorless crystal; m.p.: $152-153^{\circ} \mathrm{C} ;{ }^{1} \mathrm{H} \mathrm{NMR}\left(300 \mathrm{MHz}, \mathrm{CDCl}_{3}\right)$ $\delta 4.60(\mathrm{~d}, \mathrm{~J}=17.6 \mathrm{~Hz}, 1 \mathrm{H}), 4.75(\mathrm{br}, \mathrm{J}=15.2 \mathrm{~Hz}, 1 \mathrm{H}), 4.88(\mathrm{dd}, \mathrm{J}=15.0,2.0 \mathrm{~Hz}, 1 \mathrm{H}), 4.97$ (dd, J = 14.4, 2.3 $\mathrm{Hz}, 1 \mathrm{H}), 5.13(\mathrm{~d}, \mathrm{~J}=14.6 \mathrm{~Hz}, 1 \mathrm{H}), 7.45-7.03(\mathrm{~m}, 12 \mathrm{H}), 8.09-8.05(\mathrm{~m}, 2 \mathrm{H}) ;{ }^{13} \mathrm{C} \mathrm{NMR}\left(75 \mathrm{MHz}, \mathrm{CDCl}_{3}\right) \delta 45.54$, $47.07,87.49,121.48,124.51,127.67,128.23,128.59,128.59,128.64,128.70,129.82,131.54,135.10,135.70$, 
136.58, 148.19, 172.14, 182.13; IR (cm-1, KBr) 3430, 1736; HRMS (ESI-MS) m/z calcd for $\mathrm{C}_{23} \mathrm{H}_{19} \mathrm{O}_{4} \mathrm{~N}_{3} \mathrm{~S}-\mathrm{H}$ 432.1013, found 432.1030 .

$(R)-(+)-5-H y d r o x y-1-i s o p r o p y l-5-(3-m e t h o x y p h e n y l)-3-p h e n y l-2-t h i o h y d a n t o i n ~ 1 b$

Optical rotation: +37.6 (98\% ee) (c=1.0 in $\left.\mathrm{CHCl}_{3}\right)$; colorless crystal; m.p.: 173-174 ${ }^{\circ} \mathrm{C}$; ${ }^{1} \mathrm{H} \mathrm{NMR}(300 \mathrm{MHz}$, $\left.\mathrm{CDCl}_{3}\right) \delta 1.11(\mathrm{~d}, \mathrm{~J}=6.8 \mathrm{~Hz}, 3 \mathrm{H}), 1.22(\mathrm{~d}, \mathrm{~J}=6.8 \mathrm{~Hz}, 3 \mathrm{H}), 3.84(\mathrm{~s}, 3 \mathrm{H}), 4.39$ (sep, J = 6.9 Hz, 1H), 5.26 (br, 1H), $6.94(\mathrm{dd}, \mathrm{J}=8.0,2.1 \mathrm{~Hz}, 1 \mathrm{H}), 7.07-7.02(\mathrm{~m}, 3 \mathrm{H}), 7.20(\mathrm{t}, \mathrm{J}=2.0 \mathrm{~Hz}, 1 \mathrm{H}), 7.48-7.31(\mathrm{~m}, 4 \mathrm{H}) ;{ }^{13} \mathrm{C}$ NMR $(75$ $\left.\mathrm{MHz}, \mathrm{CDCl}_{3}\right) \delta 19.59,20.28,49.70,55.31,89.05,111.66,114.94,117.58,128.69,129.05,129.13,129.95$, 132.56, 137.27, 160.01, 173.36, 180.08; IR (cm-1, KBr) 3223, 1757; HRMS (ESI-MS) m/z calcd for $\mathrm{C}_{19} \mathrm{H}_{20} \mathrm{O}_{3} \mathrm{~N}_{2} \mathrm{~S}$ $+\mathrm{H} 357.1267$, found 357.1265 .

$(R)-(+)-5-(3-C h l o r o p h e n y l)-5-h y d r o x y-1-i s o p r o p y l-3-p h e n y l-2-t h i o h y d a n t o i n ~ 1 c$

Optical rotation: +38.9 (99 \% ee) (c=1.0 in $\mathrm{CHCl}_{3}$ ); colorless crystal; m.p.: 195-196 ${ }^{\circ} \mathrm{C}$; ${ }^{1} \mathrm{H}$ NMR $(300 \mathrm{MHz}$, $\left.\mathrm{CDCl}_{3}\right) \delta 1.09(\mathrm{~d}, \mathrm{~J}=6.8 \mathrm{~Hz}, 3 \mathrm{H}), 1.20(\mathrm{~d}, \mathrm{~J}=6.8 \mathrm{~Hz}, 3 \mathrm{H}), 4.41(\mathrm{sep}, \mathrm{J}=6.9 \mathrm{~Hz}, 1 \mathrm{H}), 5.35(\mathrm{br}, 1 \mathrm{H}), 7.03(\mathrm{~d}, \mathrm{~J}$ $=7.3 \mathrm{~Hz}, 2 \mathrm{H}), 7.51-7.34(\mathrm{~m}, 6 \mathrm{H}), 7.66(\mathrm{~s}, 1 \mathrm{H}) ;{ }^{13} \mathrm{C} \mathrm{NMR}\left(75 \mathrm{MHz}, \mathrm{CDCl}_{3}\right) \delta$ 19.67, 20.36, 49.79, 88.58, 123.64, 126.22, 128.63, 129.14, 129.30, 129.96, 130.17, 132.36, 135.18, 137.89, 173.18, 180.08; IR (cm-1 $\mathrm{KBr}) 3224$, 1757; HRMS (ESI-MS) m/z calcd for $\mathrm{C}_{18} \mathrm{H}_{17} \mathrm{O}_{2} \mathrm{~N}_{2} \mathrm{ClS}+\mathrm{Na} 383.0591$, found 383.0583 .

\section{1,3-Dimethyl-5-hydroxy-5-phenyl-2-thiohydantoin 5}

Colorless crystal; m.p.: $206{ }^{\circ} \mathrm{C} ;{ }^{1} \mathrm{H}$ NMR $\left(300 \mathrm{MHz}, \mathrm{CDCl}_{3}\right) \delta 3.10(\mathrm{~s}, 3 \mathrm{H}), 3.28(\mathrm{~s}, 3 \mathrm{H}), 4.51(\mathrm{br}, 1 \mathrm{H}), 7.39-7.34$ (m, 2H), 7.45-7.41 (m, 3H); $\left.{ }^{13} \mathrm{C} \mathrm{NMR} \mathrm{(75} \mathrm{MHz,} \mathrm{CDCl}_{3}\right) \delta$ 28.31, 29.35, 88.23, 125.62, 129.17, 129.21, 129.97, 173.13, 182.46; IR (cm-1 $\mathrm{KBr}$ ) 3291, 1722; HRMS (ESI-MS) $\mathrm{m} / \mathrm{z}$ calcd for $\mathrm{C}_{11} \mathrm{H}_{12} \mathrm{O}_{2} \mathrm{~N}_{2} \mathrm{~S}+\mathrm{H} 237.0688$, found 237.0688 .

Screening of conglomerate crystals by using SHG

The powder substrate was irradiated with Nd/YAG laser (1064 nm, $1 \mathrm{~W}$ ), and monitored by CCD video camera. When 532 nm green light, the half wave length of 1064, was observed, we concluded that it was active for SHG.

(a)

(b)
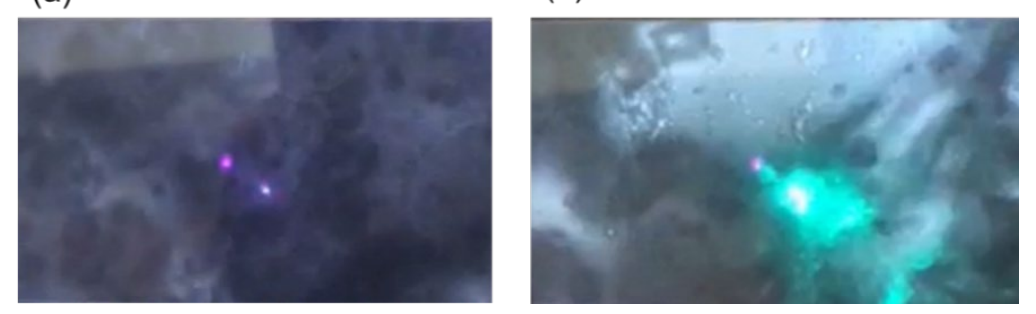

Figure S1. The captured picture of CCD video camera. (a) When the substrate was inactive for SHG, the colorless light (1064 nm) was observed in monitor; (b) When the substrate was active for SHG, the green light $(532 \mathrm{~nm})$ was observed in monitor. 
General procedure of Viedma ripening of 1a-1c.

The racemic $1(300 \mathrm{mg})$ and catalytic amount of DBU, grass beads $(\Phi=2.0 \mathrm{~mm}, 250 \mathrm{mg})$ and solvent $(1.0 \mathrm{~mL})$ were added in sealed tube. The solution was kept in suspension with vigorously stirring at $80^{\circ} \mathrm{C}$ for several days. The change of ee value of crystalline 1 was monitored by HPLC using a chiral column (Daicel ind.).

Enantiomeric purity of crystals of 1a was determined by HPLC (CHIRALPAK IC, Hex : EtOH = $95: 5$, flow 1.0 $\mathrm{mL} / \mathrm{min}, \mathrm{RT}=6.8$ and $8.1 \mathrm{~min}$ ) (Figure S6). Enantiomeric purity of crystals of $\mathbf{1 b}$ was determined by HPLC (CHIRALPAK IH-3, Hex : EtOH = $95: 5$, flow $1.0 \mathrm{~mL} / \mathrm{min}, \mathrm{RT}=15.0$ and $16.4 \mathrm{~min}$ ) (Figure S7). Enantiomeric purity of crystals of 1c was determined by HPLC (CHIRALPAK IB, Hex : EtOH = $98: 2$, flow $0.8 \mathrm{~mL} / \mathrm{min}, \mathrm{RT}=$ 8.0 and $9.4 \mathrm{~min}$ ) (Figure S7).

Enantioselectivity of deracemization of 1a-1c.

Further ten experiments were performed at optimized conditions without plotting for each 1a-1c. The ratio of times each enantiomer, $(R)$ form : $(S)$ form, was obtained were $4: 6$ for $1 \mathbf{a}, 4: 6$ for $\mathbf{1 b}$ and $5: 5$ for $\mathbf{1 c}$, respectively.

\section{DFT calculation}

The density functional theory (DFT) calculations were carried out utilizing the GAUSSIAN 16 program. ${ }^{[\text {[6] }}$ The initial geometry for the calculation of thiohydantoin $\mathbf{A}$ and $\mathbf{C}$ were set by referring to the geometry obtained by the X-ray structure analysis of 1a-1c. On the other hand, the initial geometry for the calculation of opened form $\mathbf{B}$ and $\mathbf{D}$ were set by semi-empirical molecular orbital method PM6.[S7] The optimization of A-D was carried out at the B3LYP/6-31G* level; vibrational frequency analysis revealed no imaginary frequencies, confirming A-D to be in true energy minima. 
Racemization of dimethylthiohydantoin 5

Half-life: $3792 \mathrm{~min}$ (in toluene, $90^{\circ} \mathrm{C}$ ), $341 \mathrm{~min}$ (in propanol $80^{\circ} \mathrm{C}$ ).
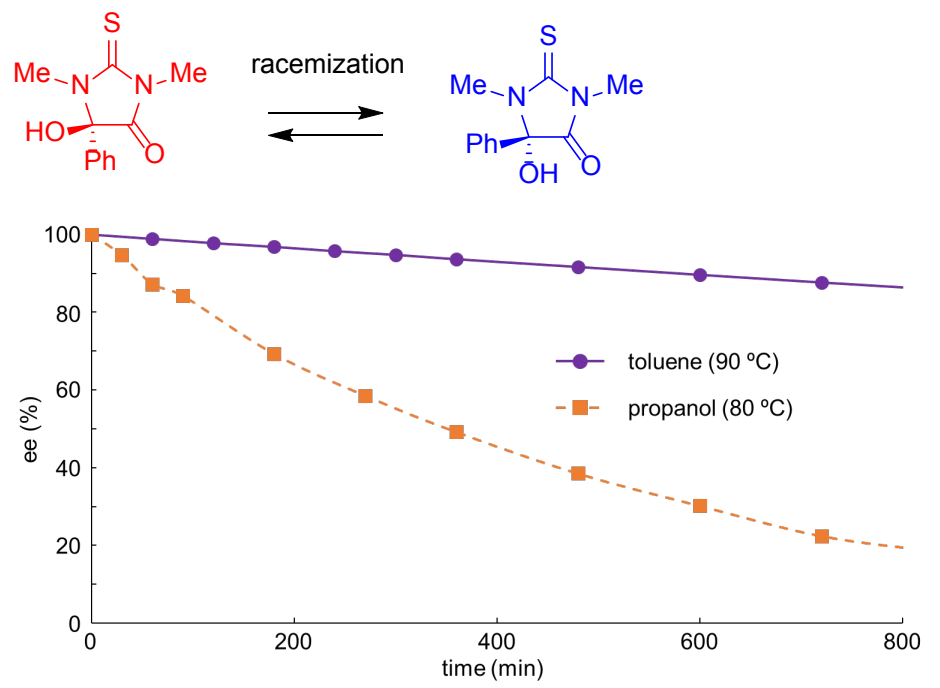

Figure S2. The time course of racemization of 5 at $90^{\circ} \mathrm{C}$ in toluene (solid lines) and at $80^{\circ} \mathrm{C}$ in propanol (dashed lines).

\section{References}

[S1] A. Lu, A. Wang, Z. Zhou, J. Chen, Q. Wang, J. Agric. Food Chem. 2015, 63, 1378-1384.

[S2] V. Štrukil, M. D. Igrc, L. Fábián, M. Eckert-Maksić, S. L. Childs, D. G. Reid, M. J. Duer, I. Halasz, C. Mottillo, T. Friščić, Green Chem. 2012, 14, 2462-2473.

[S3] H. Shimizu, M. Murakami, Chem. Commun. 2007, 2855-2857.

[S4] M. Juhl, J. W. Lee, Angew. Chem. Int. Ed. 2018, 57, 12318-12322.

[S5] M. Meng, G. Wang, L. Yang, K. Cheng, C. Qi, Adv. Synth. Catal. 2018, 360, 1218-1231.

[S6] Gaussian 16, Revision B.01, M. J. Frisch, G. W. Trucks, H. B. Schlegel, G. E. Scuseria, M. A. Robb, J. R. Cheeseman, G. Scalmani, V. Barone, G. A. Petersson, H. Nakatsuji, X. Li, M. Caricato, A. V. Marenich, J. Bloino, B. G. Janesko, R. Gomperts, B. Mennucci, H. P. Hratchian, J. V. Ortiz, A. F. Izmaylov, J. L. Sonnenberg, D. Williams-Young, F. Ding, F. Lipparini, F. Egidi, J. Goings, B. Peng, A. Petrone, T. Henderson, D. Ranasinghe, V. G. Zakrzewski, J. Gao, N. Rega, G. Zheng, W. Liang, M. Hada, M. Ehara, K. Toyota, R. Fukuda, J. Hasegawa, M. Ishida, T. Nakajima, Y. Honda, O. Kitao, H. Nakai, T. Vreven, K. Throssell, J. A. Montgomery, Jr., J. E. Peralta, F. Ogliaro, M. J. Bearpark, J. J. Heyd, E. N. Brothers, K. N. Kudin, V. N. Staroverov, T. A. Keith, R. Kobayashi, J. Normand, K. Raghavachari, A. P. Rendell, J. C. Burant, S. S. Iyengar, J. Tomasi, M. Cossi, J. M. Millam, M. Klene, C. Adamo, R. Cammi, J. W. Ochterski, R. L. Martin, K. Morokuma, O. Farkas, J. B. Foresman, and D. J. Fox, Gaussian, Inc., Wallingford CT, 2016.

[S7] J. J. P. Stewart, Optimization of parameters for semiempirical methods. V. Modification of NDDO approximations and application to 70 elements, J. Mol. Model. 2007, 13, 1173-1213. 
Single-crystal X-ray structure analysis of $1 \mathbf{a}$

Colorless plate, $\left(0.20 \times 0.20 \times 0.01 \mathrm{~mm}^{3}\right)$, orthorhombic space group $P 2{ }_{12}{ }_{12}, a=7.5425(2) \mathrm{A}, b=$ 13.6714(3) $\AA, c=20.4017(6) \AA, V=2103.75(10) \AA^{3}, Z=4, \lambda($ CuK $\alpha)=1.54178 \AA, \rho=1.369 \mathrm{~g} / \mathrm{cm}^{3}, \mu($ CuK $\alpha)$ $=1.670 \mathrm{~mm}^{-1}, 25055$ reflections measured $\left(T=173 \mathrm{~K}, 3.892^{\circ}<\theta<68.455^{\circ}\right)$, nb of independent data collected: $3846, \mathrm{nb}$ of independent data used for refinement: 3784 in the final least-squares refinement cycles on $\mathrm{F}^{2}$, the model converged at $R_{1}=0.0791, w R_{2}=0.1760[\mathrm{I}>2 \sigma(\mathrm{I})], R_{1}=0.0798, w R_{2}=0.1763$ (all data), and GOF = $1.245, \mathrm{H}$-atom parameters constrained. Flack parameter $=0.081(7)$ for $(R)$-configuration.

CCDC 1999351 (for 1a) contains the supplementary crystallographic data for this paper. These data can be obtained free of charge from The Cambridge Crystallographic Data Centre.

A 2-fold helix was constructed along all axes; however, a column constructed by strong intermolecular hydrogen bonding between the carbonyl oxygen and the hydroxyl groups $(\mathrm{C}=\mathrm{O}---\mathrm{H}-\mathrm{O}: 1.904 \AA$ ) was formed along the aaxis (Figure S3). Each column was supported by weak hydrogen bonds between the thiocarbonyl sulfur atom and the aromatic hydrogen (C=S---H-Ph: $2.917 \AA$ ) and $\mathrm{NO}_{2}---\mathrm{H}-\mathrm{Ph}(2.664 \AA)$.

(a)

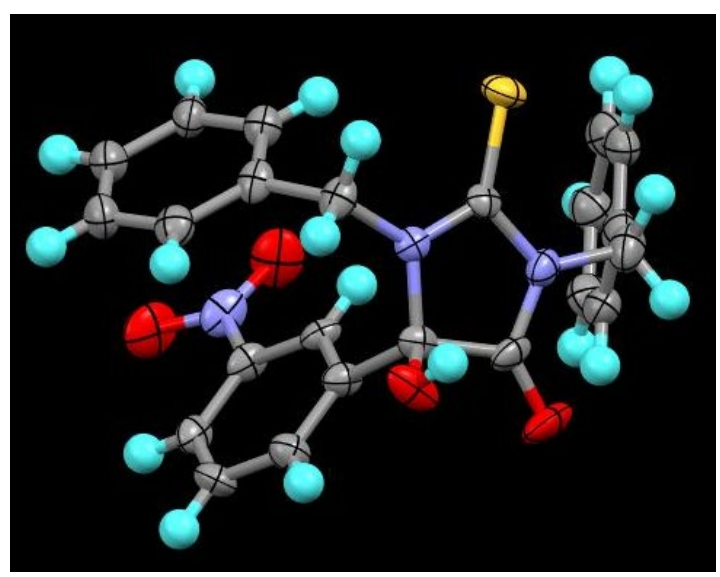

(b)

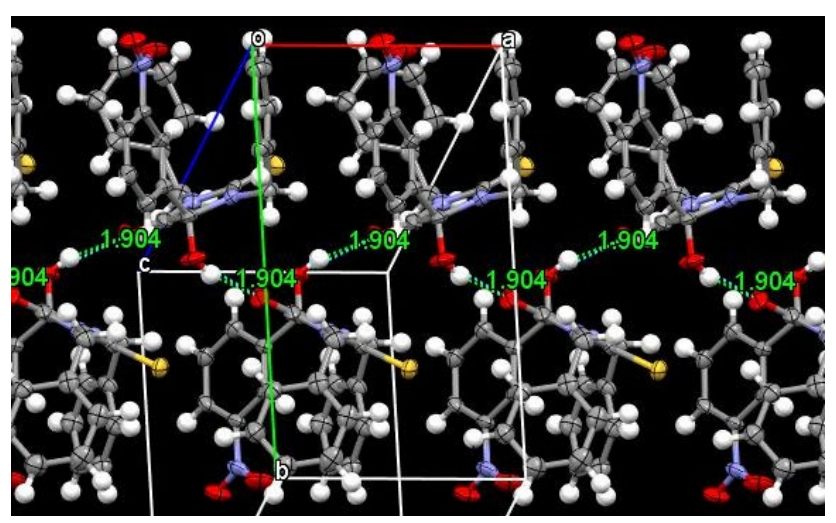

(c)

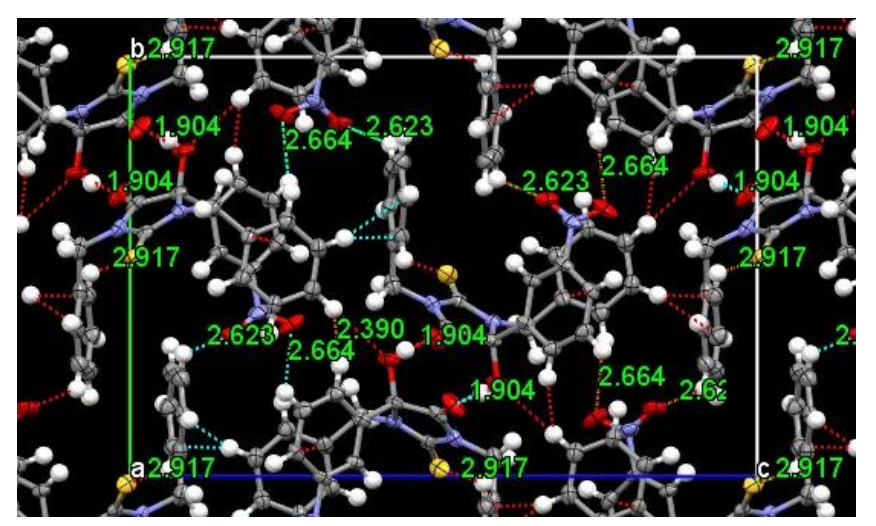

Figure S3. X-Ray structure analysis for $(R)-1$ a. (a) View of 2-fold helix along the a-axis by $\mathrm{C}=\mathrm{O}---\mathrm{H}-\mathrm{OC}$ hydrogen bonding $(1.904 \AA$ ). (b) View along the a-axis showing the array of columns by the hydrogen bond interactions between $\mathrm{C}=\mathrm{S}$ and $\mathrm{H}-\mathrm{Ph}(2.917 \AA)$ and $\mathrm{NO}_{2}---\mathrm{H}-\mathrm{Ph}(2.664 \AA)$. 
Single-crystal X-ray structure analysis of $\mathbf{1 b}$

Colorless needle, $\left(0.20 \times 0.20 \times 0.01 \mathrm{~mm}^{3}\right)$, monoclinic space group $P 2{ }_{1}, a=11.4495(4) \AA, b=5.7017(2)$ $\AA, c=14.0950(5) \AA, \beta=107.697(2)^{\circ}, V=876.60(5) \AA^{3}, Z=2, \lambda($ CuK $\alpha)=1.54178 \AA, \rho=1.350 \mathrm{~g} / \mathrm{cm}^{3}, \mu($ CuK $\alpha)$ $=1.814 \mathrm{~mm}^{-1}, 13501$ reflections measured $\left(T=173 \mathrm{~K}, 3.291^{\circ}<\theta<68.350^{\circ}\right)$, nb of independent data collected: $3161, \mathrm{nb}$ of independent data used for refinement: 3010 in the final least-squares refinement cycles on $\mathrm{F}^{2}$, the model converged at $R_{1}=0.0281, w R_{2}=0.0723[\mathrm{I}>2 \sigma(\mathrm{I})], R_{1}=0.0301, w R_{2}=0.0732$ (all data), and GOF = $1.064 \mathrm{H}$-atom parameters constrained. Flack parameter $=0.035(6)$ for $(R)$-configuration.

CCDC 1999352 (for 1b) contains the supplementary crystallographic data for this paper. These data can be obtained free of charge from The Cambridge Crystallographic Data Centre.

A 2-fold helix was constructed along the $b$-axis where a hydrogen bond between the thiocarbonyl sulfur atom and hydroxyl group forms a column (C=S---H-O: $2.365 \AA$ ) (Figure S4). The columns spanned in another direction by S---S interactions with other columns with a distance of $3.569 \AA$, a weak hydrogen bond between $\mathrm{C}=\mathrm{O}$ and $\mathrm{H}-\mathrm{Ph}(2.624 \AA)$, and a $\mathrm{CH}-\pi$ interaction between the methoxy methyl group and phenyl ring (3.230 $\AA$ ).

(a)

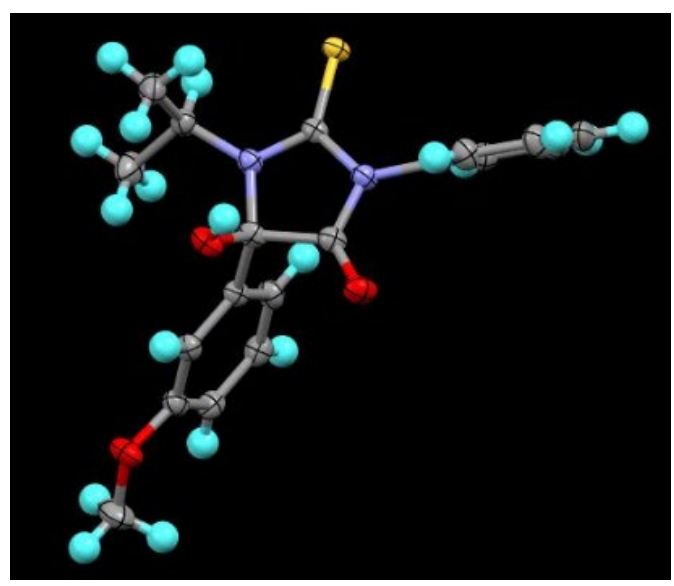

(b)

(c)

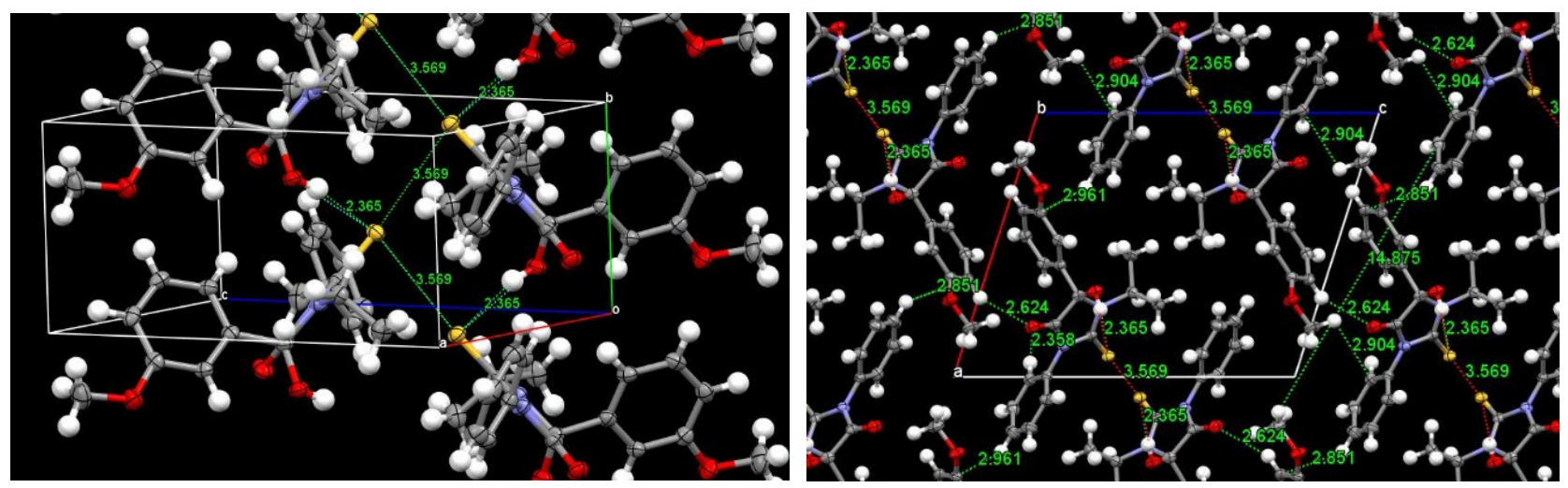

Figure S4. Packing diagram for $(R)-1 \mathbf{b}$. (a) View of 2-fold helix along $b$-axis by $\mathrm{C}=\mathrm{S}---\mathrm{H}-\mathrm{OC}$ hydrogen bonding $(2.365 \AA)$. (b) View along the b-axis showing the array of columns by the interactions of S-S (3.569 $\AA$ ), C=O--$\mathrm{H}-\mathrm{Ph}(2.624 \AA)$, and $\mathrm{CH}---\pi(2.904 \AA)$. 
Single-crystal X-ray structure analysis of 1c

Colorless plate, $\left(0.30 \times 0.20 \times 0.05 \mathrm{~mm}^{3}\right)$, monoclinic space group $P 21, a=11.7753(5) \AA, b=5.7683(3) \AA, c=$ 13.2106(6) $\AA, \beta=105.956(2)^{\circ}, V=862.74(7) \AA^{3}, Z=2, \lambda(\operatorname{CuK} \alpha)=1.54178 \AA, \rho=1.389 \mathrm{~g} / \mathrm{cm}^{3}, \mu(\mathrm{CuK} \alpha)=$ $3.198 \mathrm{~mm}^{-1}, 10142$ reflections measured $\left(T=173 \mathrm{~K}, 3.480^{\circ}<\theta<68.297^{\circ}\right)$, nb of independent data collected: $3099, \mathrm{nb}$ of independent data used for refinement: 3016 in the final least-squares refinement cycles on $\mathrm{F}^{2}$, the model converged at $R_{1}=0.0259, w R_{2}=0.0644[\mathrm{l}>2 \sigma(\mathrm{l})], R_{1}=0.0264, w R_{2}=0.0647$ (all data), and GOF = $1.033 \mathrm{H}$-atom parameters constrained. Flack parameter $=0.045(5)$ for $(R)$-configuration.

CCDC 1999353 (for 1c) contains the supplementary crystallographic data for this paper. These data can be obtained free of charge from The Cambridge Crystallographic Data Centre.

There is a 2 -fold helix along the $b$-axis connected by hydrogen bonding between the thiocarbonyl sulfur atom and hydroxyl group ( $\mathrm{C}=\mathrm{S}$--- $\mathrm{H}-\mathrm{O}: 2.376 \AA$ ). The columns were spanned by $\mathrm{Cl}-\mathrm{H}-\mathrm{Ph}$ interactions with other columns with a distance of $2.772 \AA$ and a hydrogen bond between $\mathrm{C}=\mathrm{O}$ and $\mathrm{H}-\mathrm{Ph}(2.475 \AA)$.

(a)

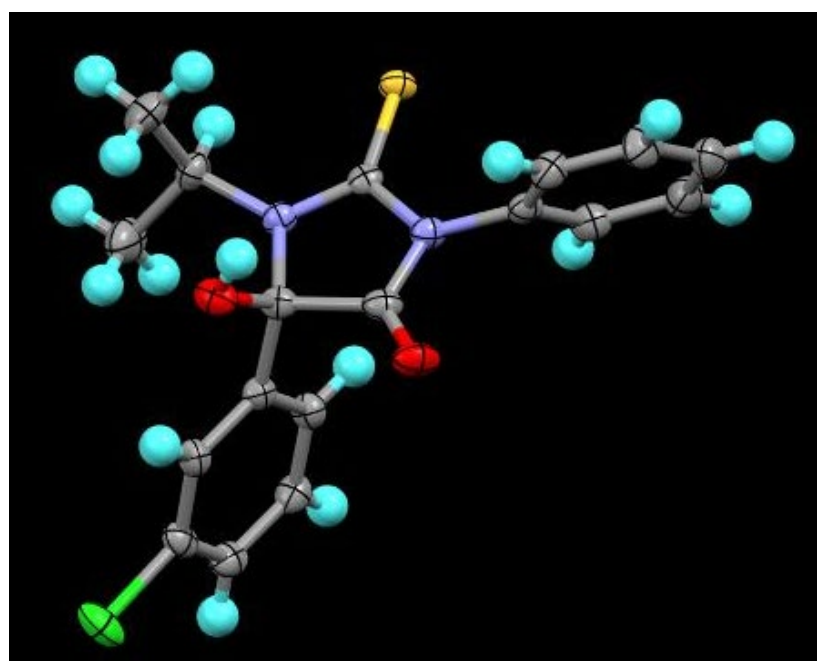

(b)

(c)
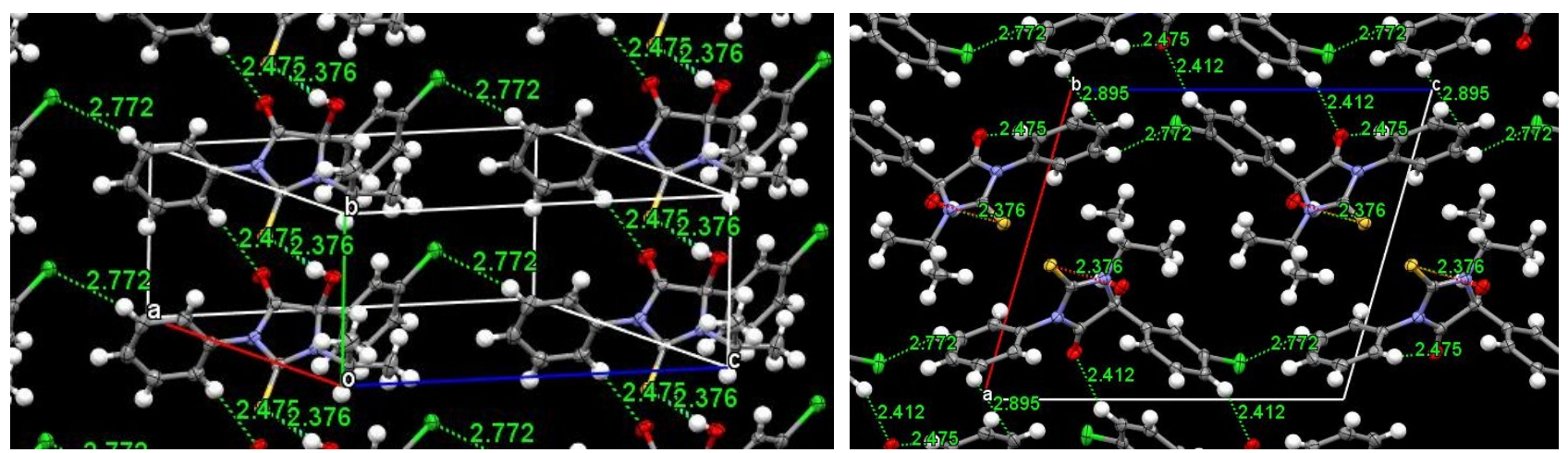

Figure S5. Packing diagram for $(R)-1 \mathrm{c}$. (a) View of 2-fold helix along $b$-axis by $\mathrm{C}=\mathrm{S}---\mathrm{H}-\mathrm{OC}$ hydrogen bonding.

(b) View along $b$-axis showing the array of the columns spanned by the $\mathrm{Cl}---\mathrm{H}-\mathrm{Ph}$ interaction with other columns with a distance of $2.772 \AA$ and a hydrogen bond between $\mathrm{C}=\mathrm{O}$ and $\mathrm{H}-\mathrm{Ph}(2.475 \AA)$. 
Figure S6. HPLC analysis of racemic 1a using CHIRALPAK IC.
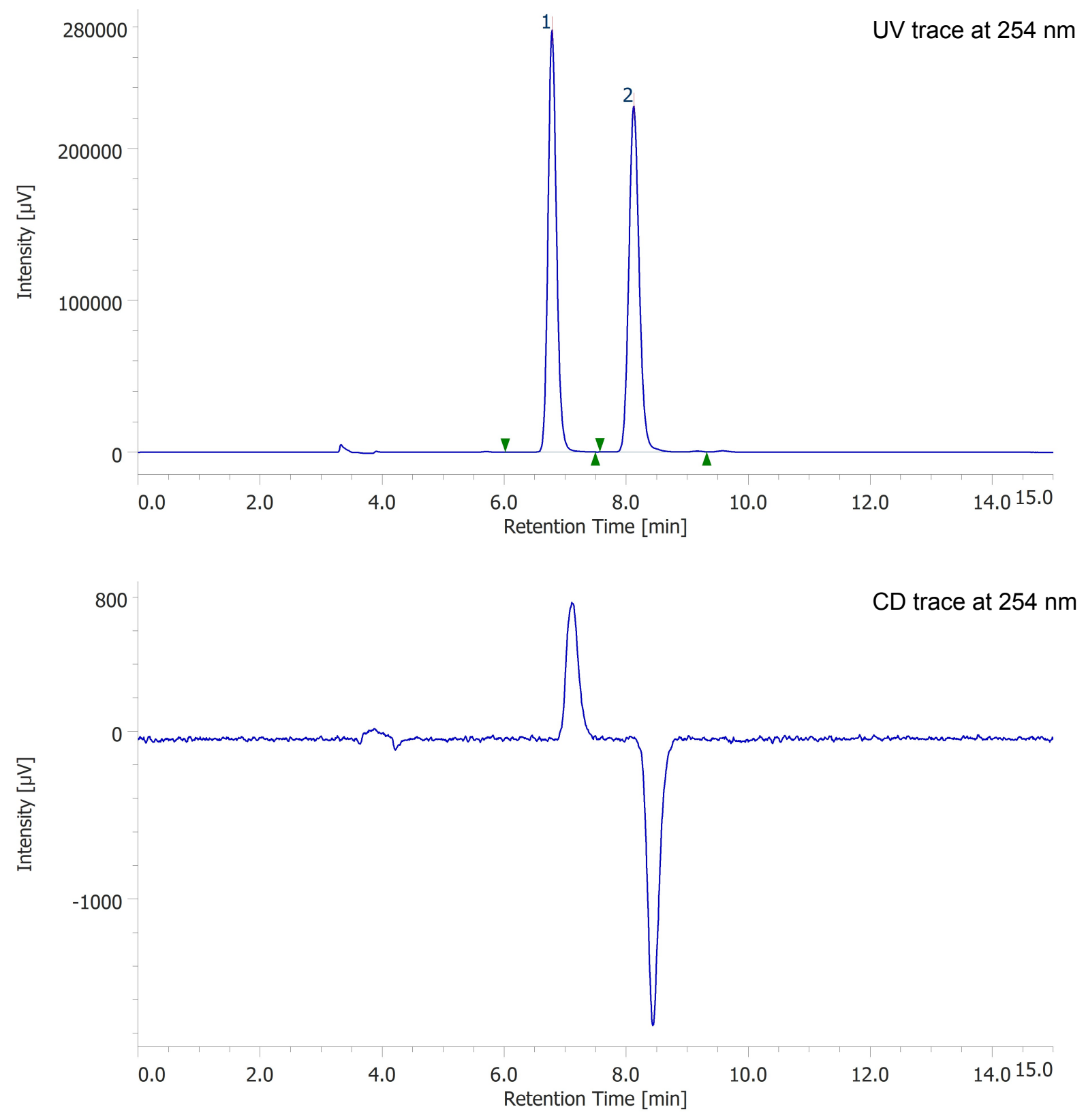

Column : CHIRALPAK-IC

Flow rate : $1.0 \mathrm{~mL} / \mathrm{min}$

Eluent : Hexane : $\mathrm{EtOH}=95: 5$ 
Figure S7. HPLC analysis of $92 \%$ ee of 1 a using CHIRALPAK IC.
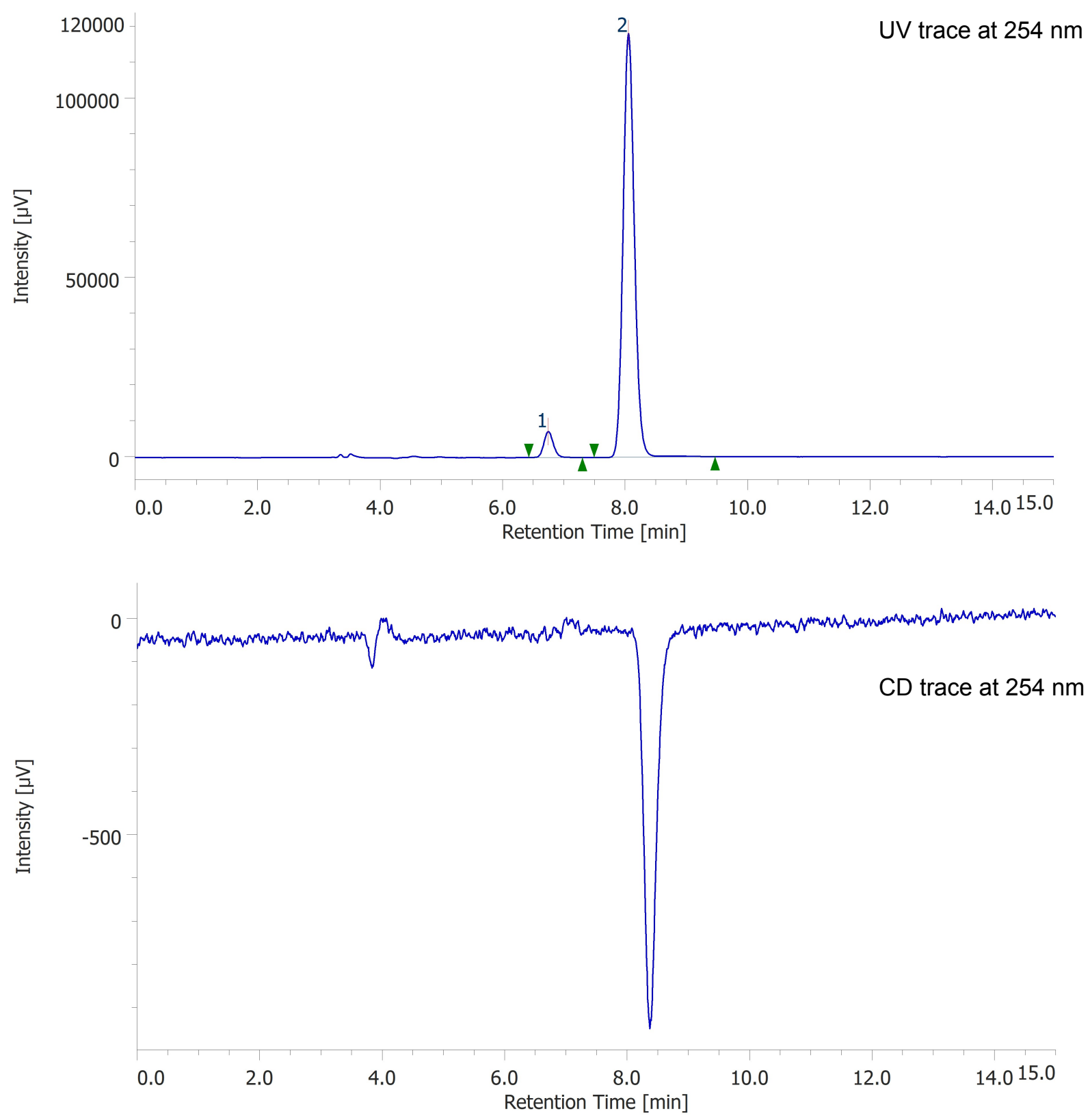

Column : CHIRALPAK-IC

Flow rate : $1.0 \mathrm{~mL} / \mathrm{min}$

Eluent : Hexane : EtOH $=95: 5$ 
Figure S8. HPLC analysis of racemic 1b using CHIRALPAK IH-3.
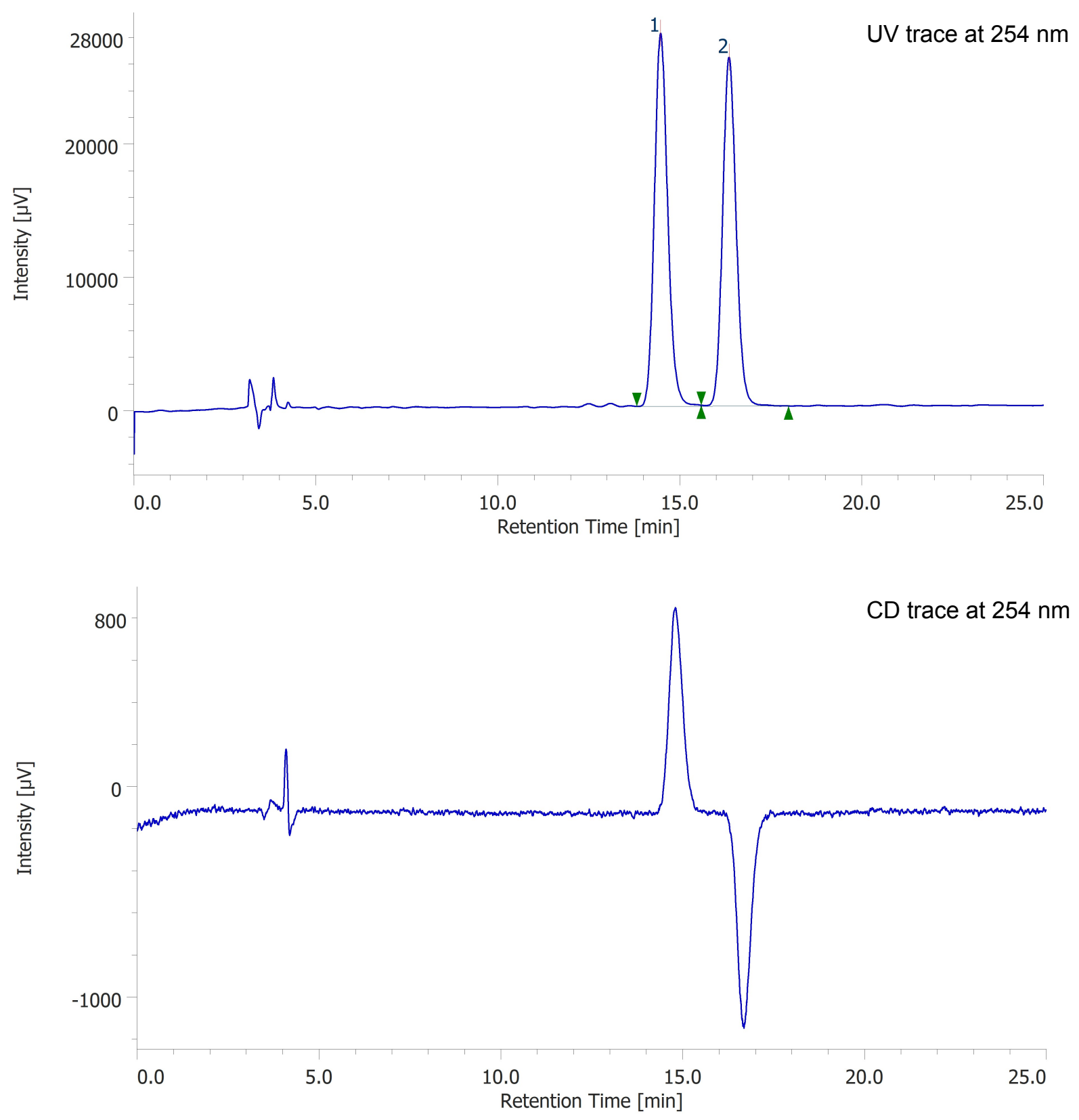

Column : CHIRALPAK-IH-3

Flow rate : $1.0 \mathrm{~mL} / \mathrm{min}$

Eluent : Hexane : $\mathrm{EtOH}=95: 5$ 
Figure S9. HPLC analysis of $94 \%$ ee of $1 \mathbf{b}$ using CHIRALPAK IH-3.
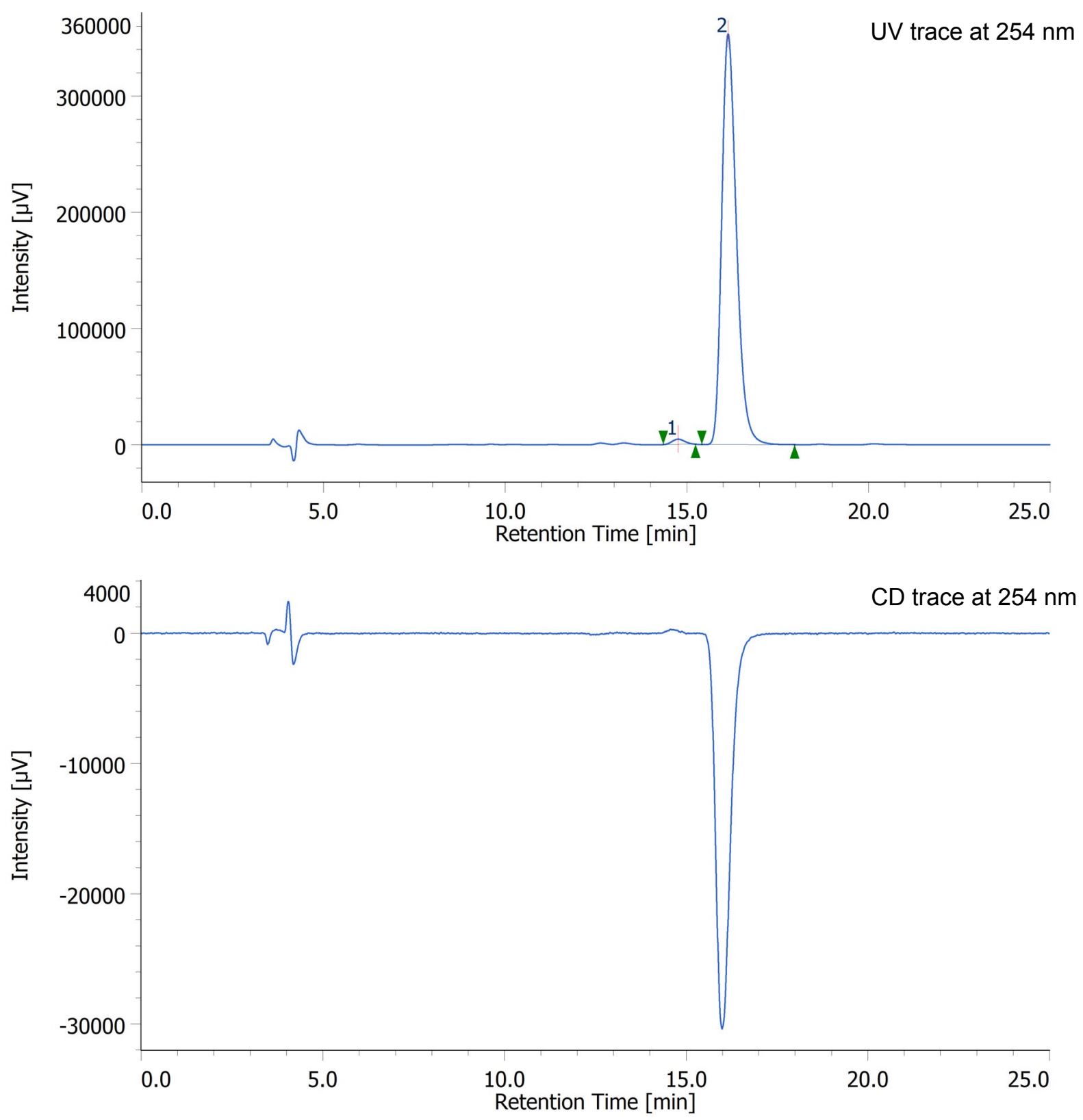

Column : CHIRALPAK-IH-3

Flow rate : $1.0 \mathrm{~mL} / \mathrm{min}$

Eluent : Hexane : EtOH $=95: 5$ 
Figure S10. HPLC analysis of racemic 1c using CHIRALPAK IH-3.
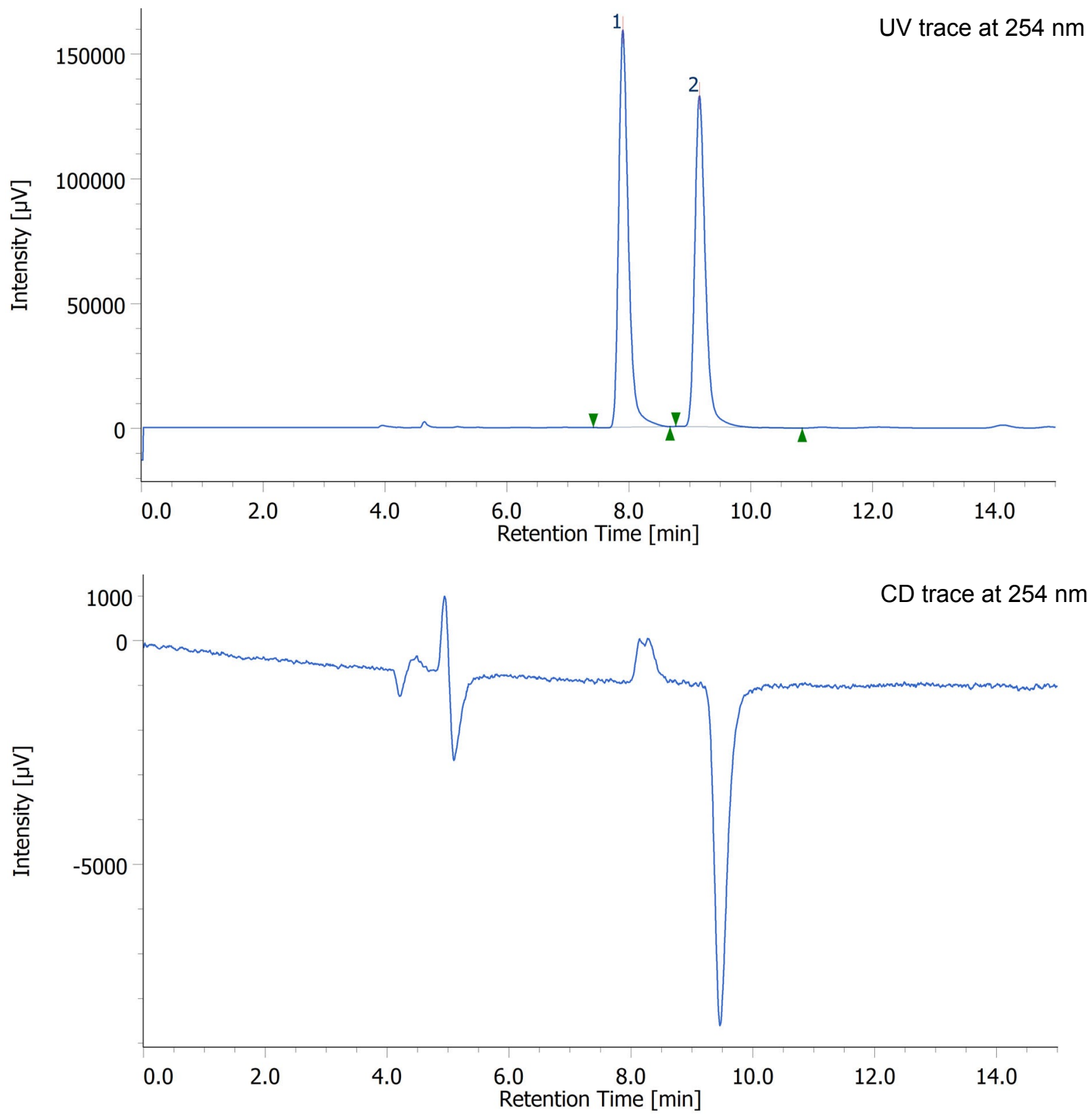

Column : CHIRALPAK-IH-3

Flow rate : $0.8 \mathrm{~mL} / \mathrm{min}$

Eluent : Hexane : EtOH $=92: 8$ 
Figure S11. HPLC analysis of $96 \%$ ee of 1c using CHIRALPAK IH-3.
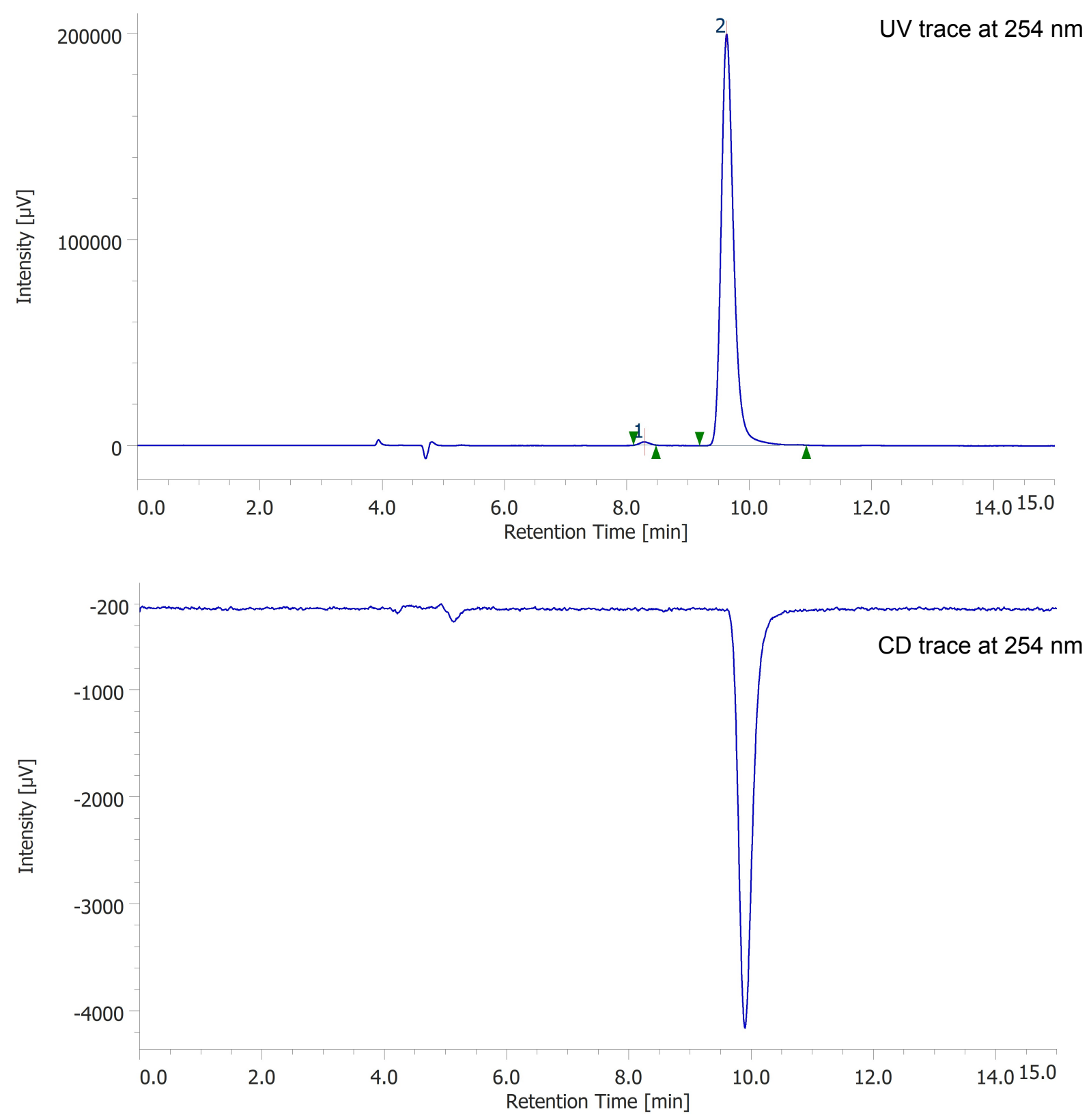

Column : CHIRALPAK-IH-3

Flow rate : $0.8 \mathrm{~mL} / \mathrm{min}$

Eluent : Hexane : EtOH $=92: 8$ 
Figure S12. ${ }^{1} \mathrm{H}$ NMR spectrum of $1 \mathrm{a}$

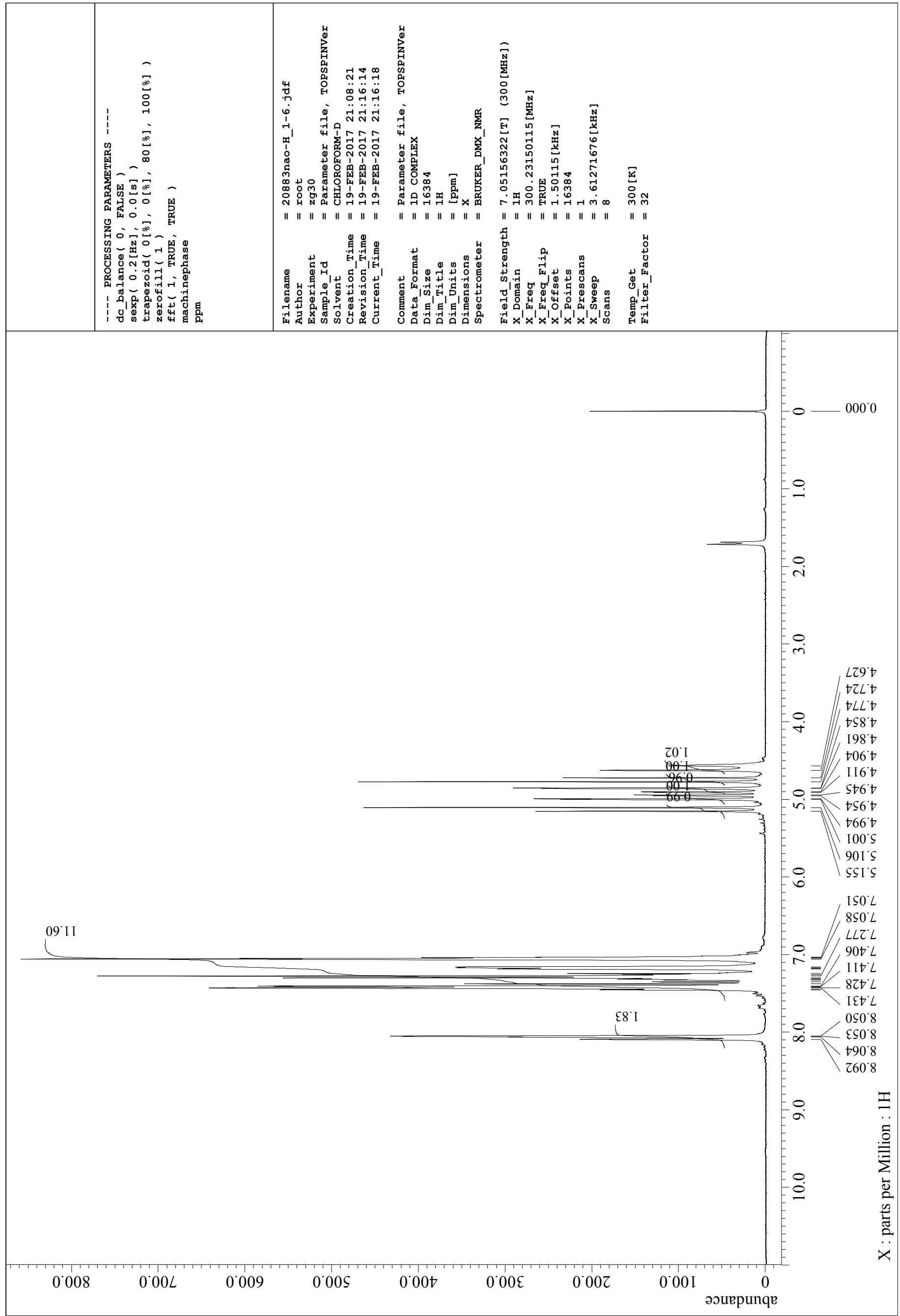


Figure $\mathrm{S} 13 \cdot{ }^{13} \mathrm{C}$ NMR spectrum of $1 \mathrm{a}$

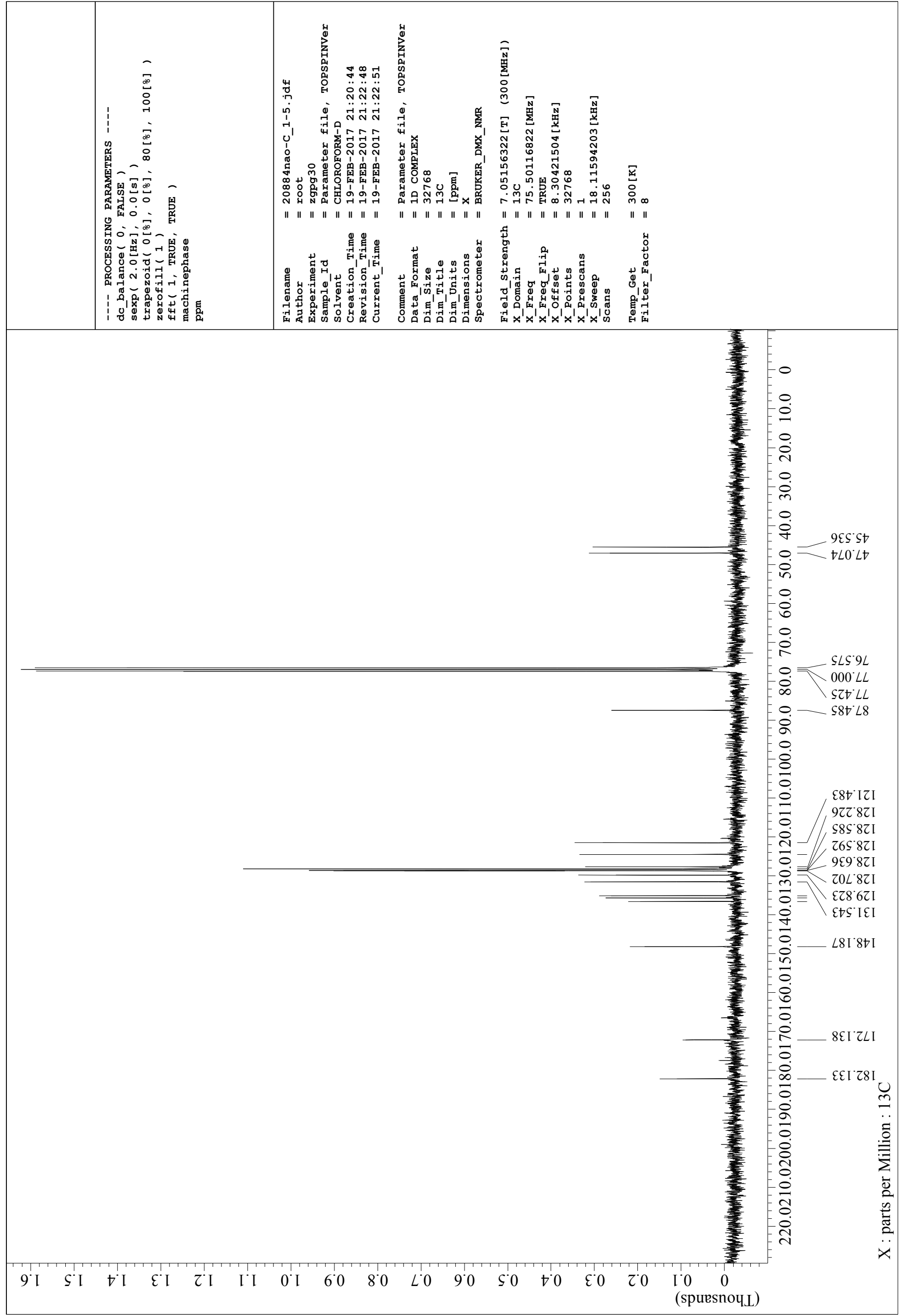


Figure $\mathrm{S} 14 .{ }^{1} \mathrm{H}$ NMR spectrum of $1 \mathrm{~b}$

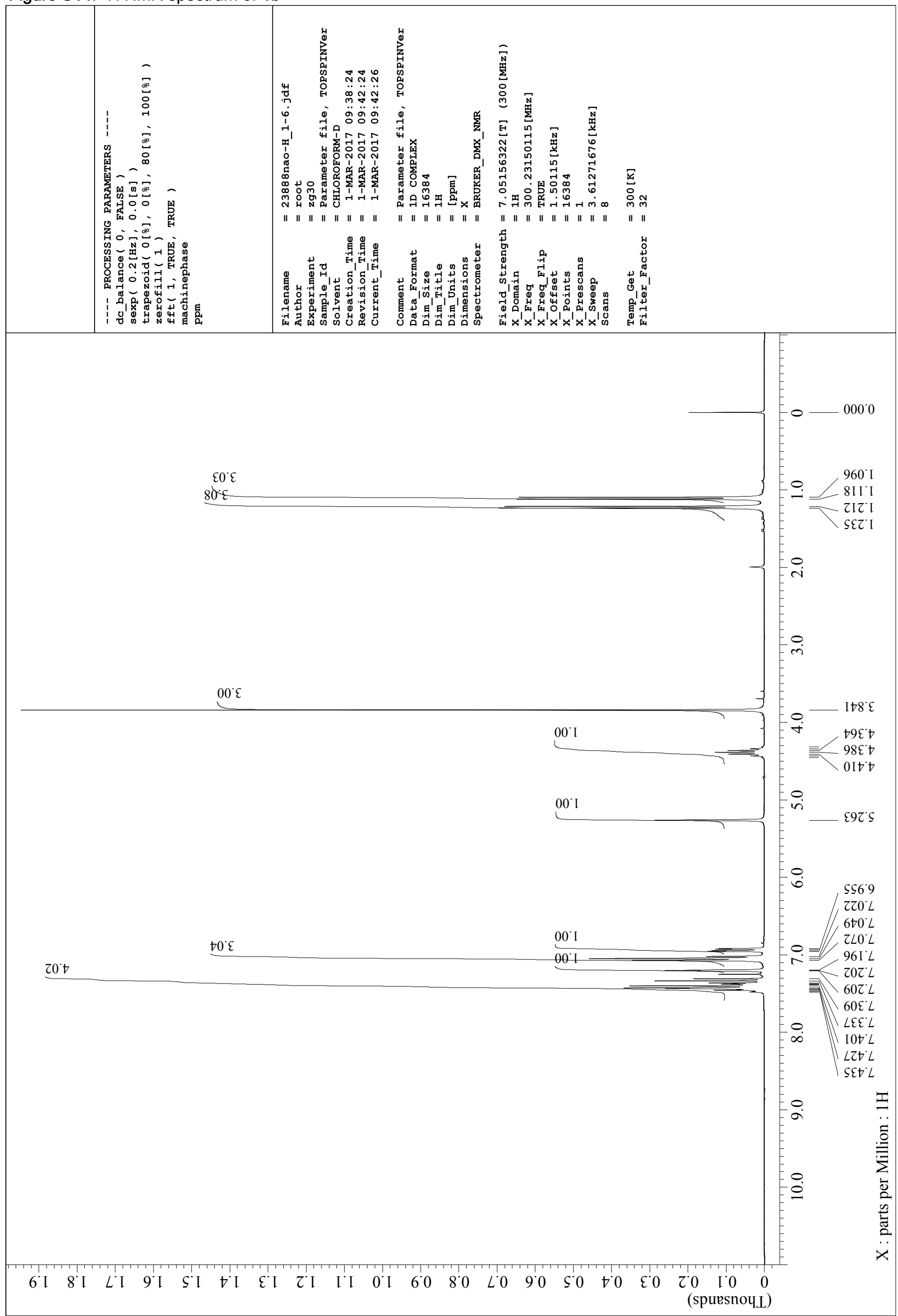


Figure S15. ${ }^{13} \mathrm{C}$ NMR spectrum of $1 \mathrm{~b}$

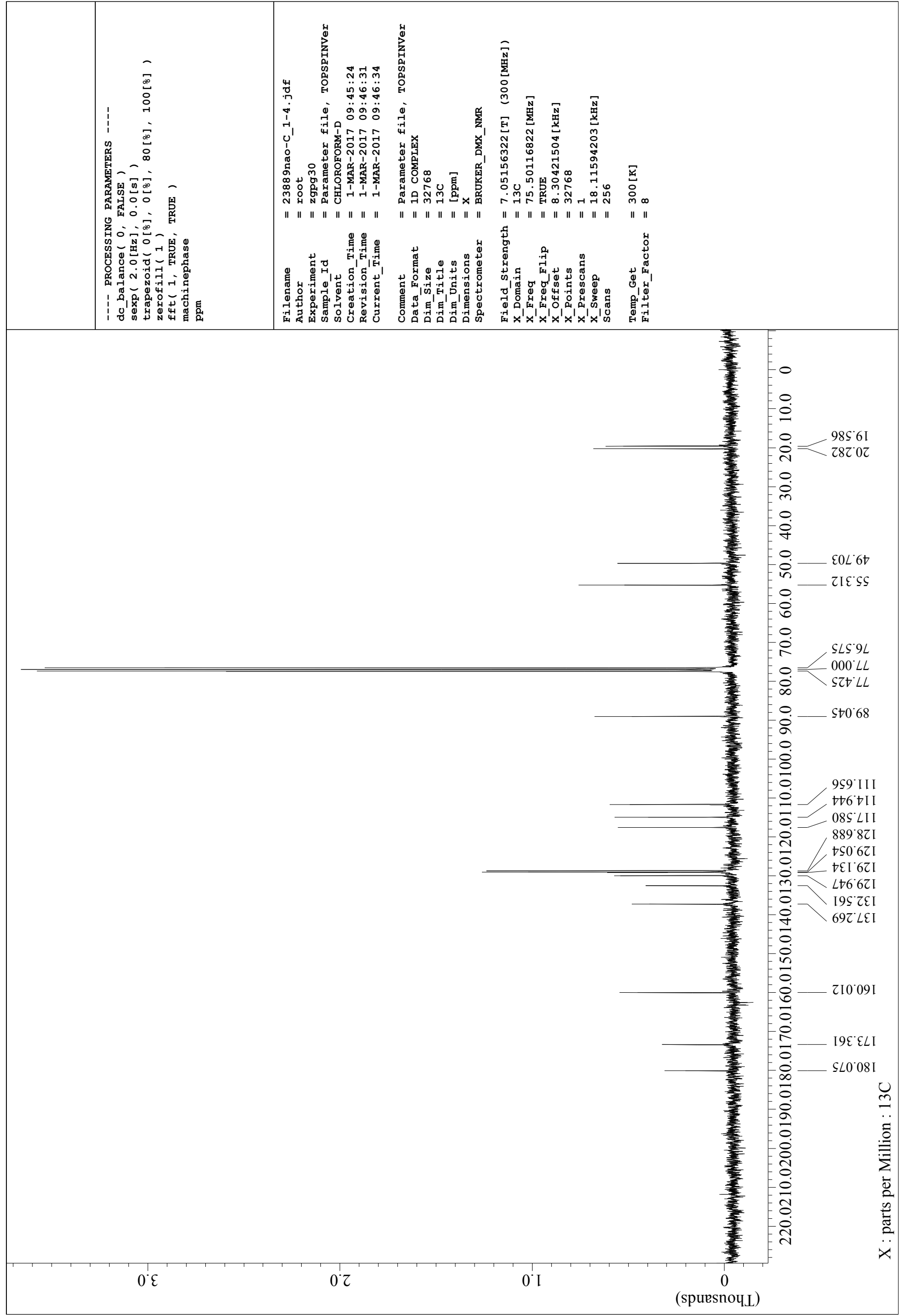


Figure S16. ${ }^{1} \mathrm{H}$ NMR spectrum of $1 \mathrm{c}$

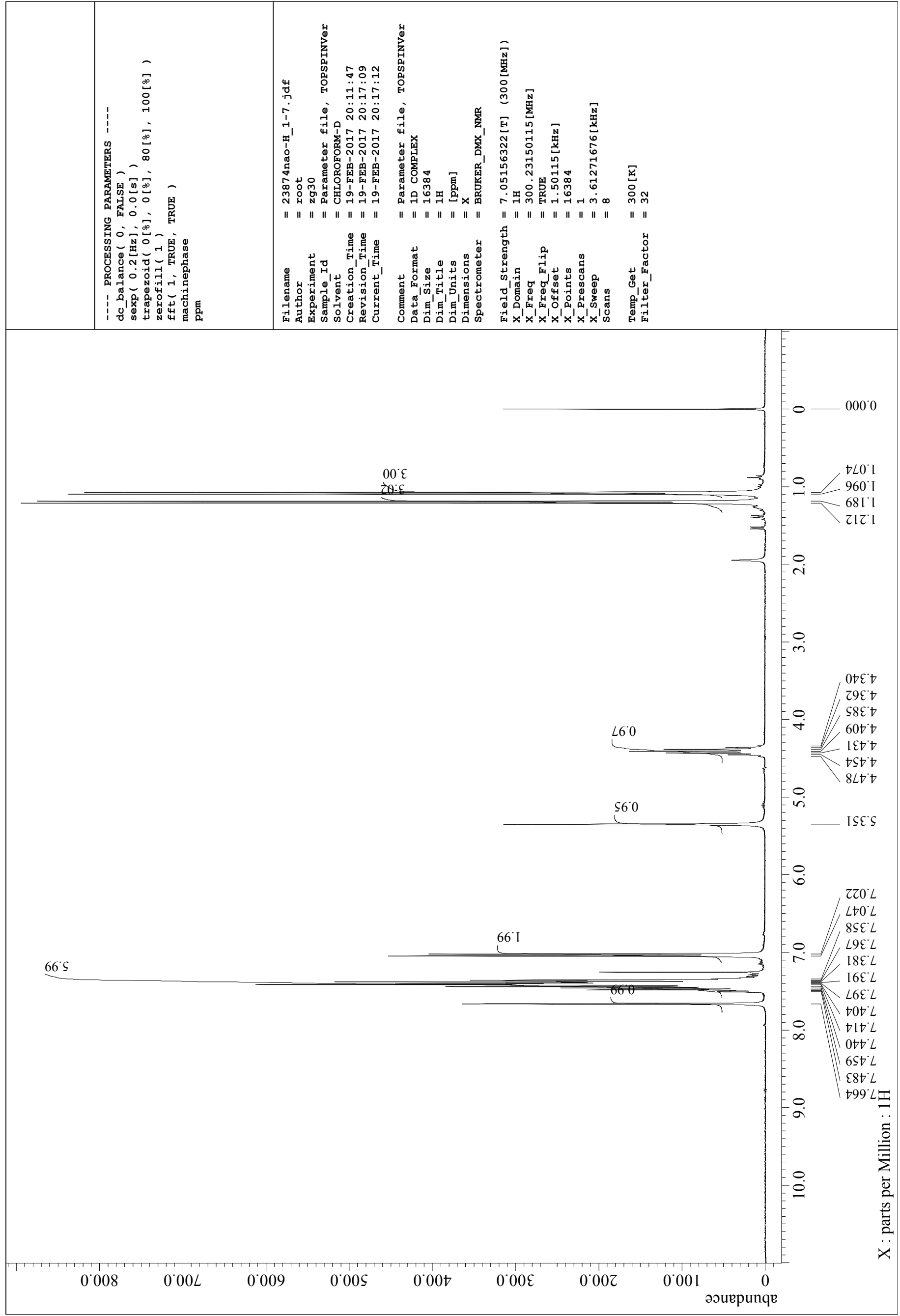


Figure S17. ${ }^{13} \mathrm{C}$ NMR spectrum of $1 \mathrm{c}$

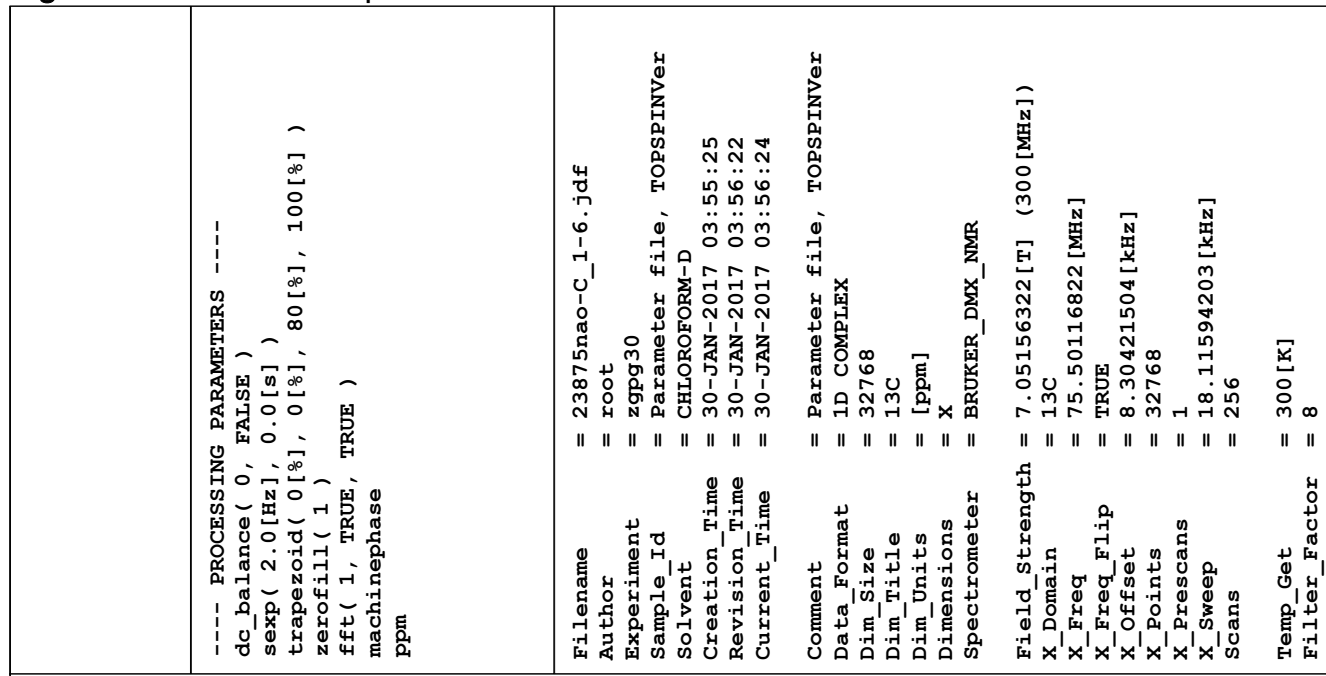

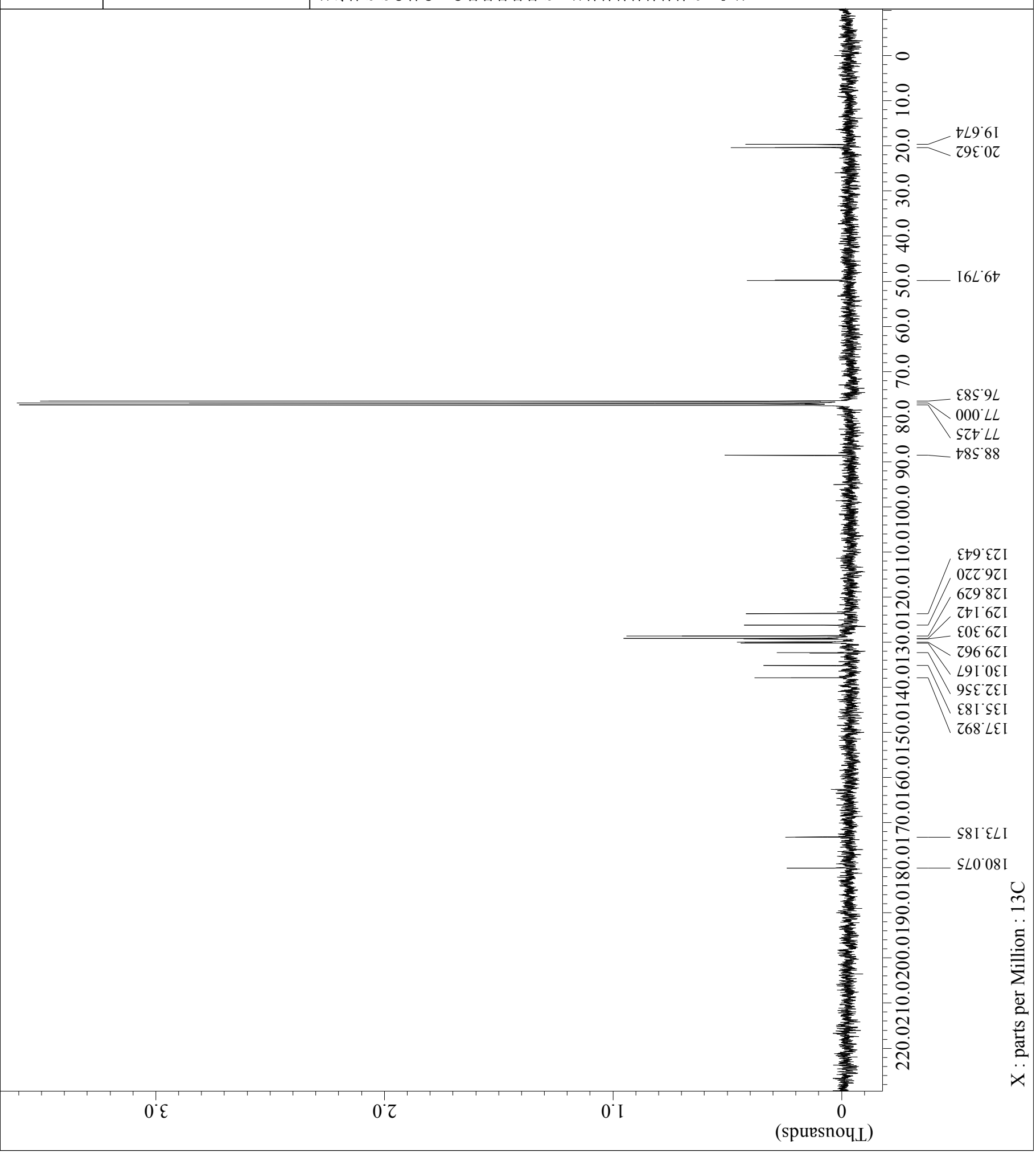


Figure S18. ${ }^{1} \mathrm{H}$ NMR spectrum of 5

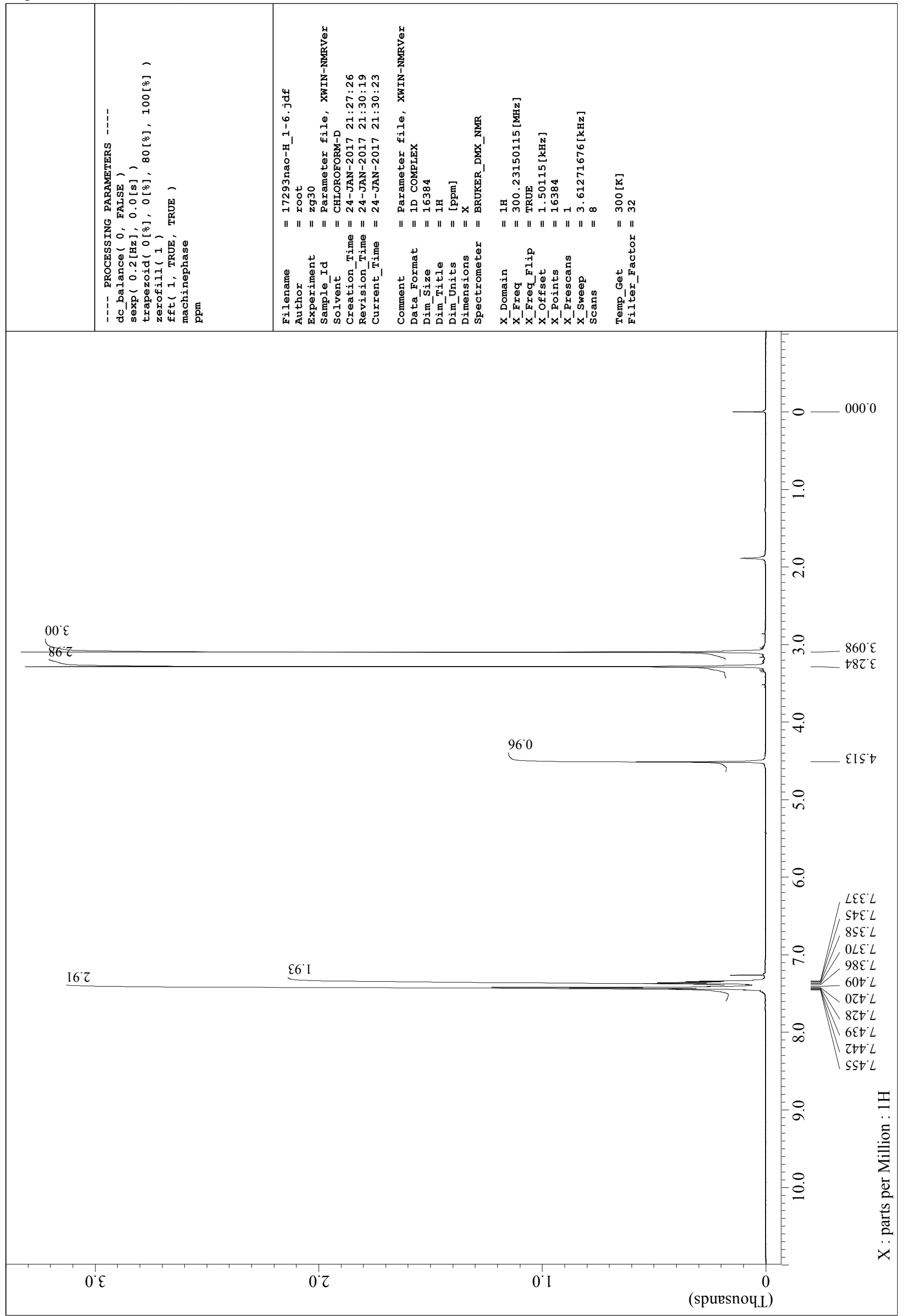


Figure S19. ${ }^{13} \mathrm{C}$ NMR spectrum of 5

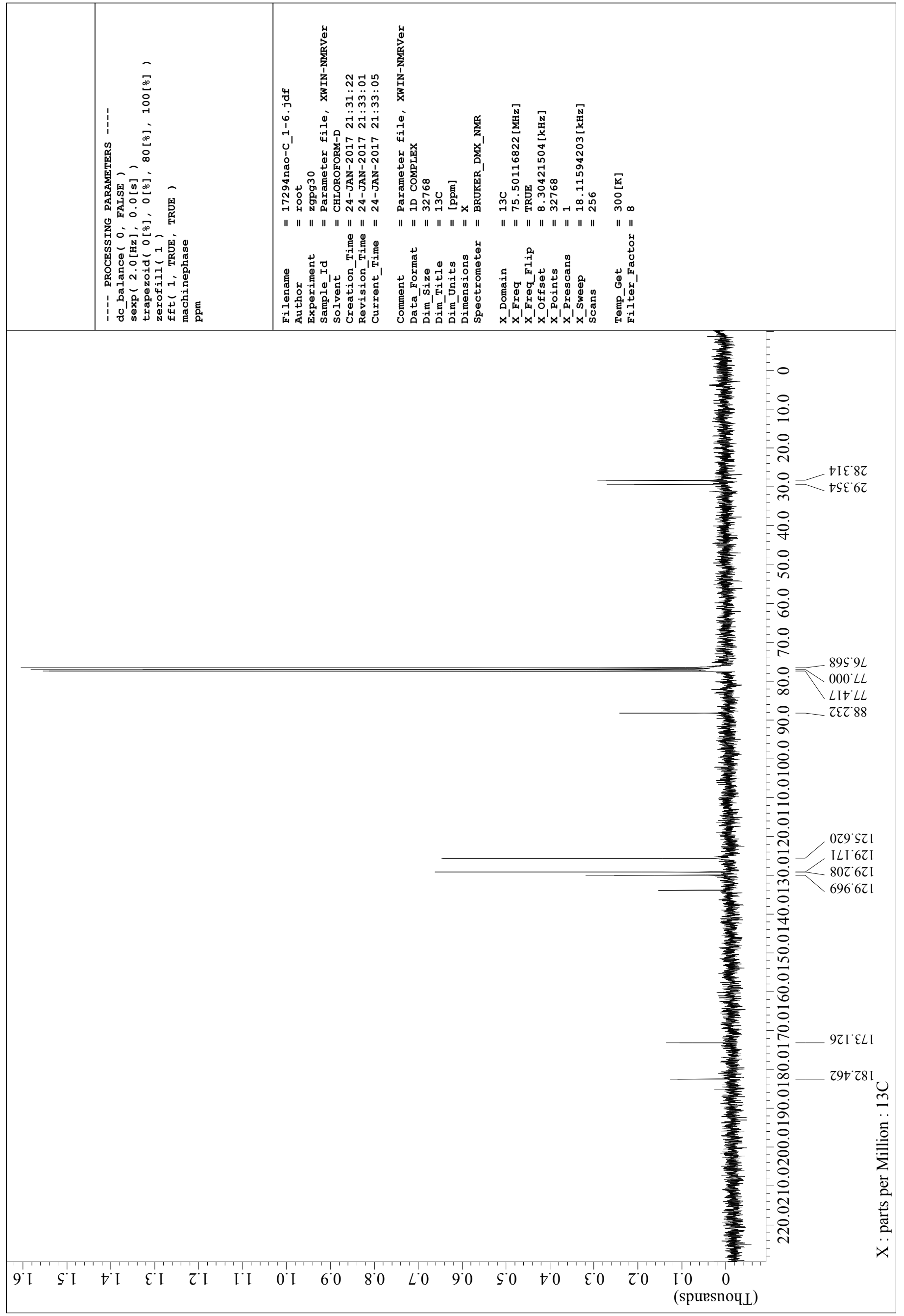

